\title{
LASP2 suppressed malignancy and Wnt/ $\beta$-catenin signaling pathway activation in bladder cancer
}

\author{
RONGQUAN YANG $^{1}$, ZEMING LIAO ${ }^{1}$, YONG CAI $^{1}$ and JINGJING KONG ${ }^{2}$ \\ Departments of ${ }^{1}$ Urology and ${ }^{2}$ Anesthesia, The First People's Hospital of Jingmen, Jingmen, Hubei 448000, P.R. China
}

Received April 3, 2018; Accepted September 27, 2018

DOI: $10.3892 /$ etm.2018.6836

\begin{abstract}
LIM and SH3 Protein 2 (LASP2), a member of the nebulin family of actin-binding proteins, is associated with the development of cancers. However, little was known about the role of LASP2 in human bladder cancer. In the current study, LASP 2 expression was evaluated by reverse transcription-quantitative polymerase chain reaction analysis in bladder cancer cell lines and tissue samples. The role of LASP2 in cancer cell proliferation, migration and invasion, and angiogenesis was explored. The association between prognostic outcomes and LASP2 expression were examined using Kaplan-Meier analysis. LASP2 expression was decreased in bladder cancer cells and tissues. LASP2 expression was associated with tumor size $(\mathrm{P}=0.016)$ and $\mathrm{T}$ classification $(\mathrm{P}=0.001)$. Patients with lower LASP2 expression had shorter overall and recurrent-free survival times. Overexpression of LASP2 inhibited and silencing of LASP2 promoted the proliferation, migration and invasion of bladder cancer cells, and angiogenesis in bladder cancer. Furthermore, it was determined that the tumor suppressing effect of LASP2 may be associated with the inactivation of the Wnt/ $\beta$-catenin signaling pathway. LASP2 may represent a novel and useful prognostic indicator, and could serve as a potential therapeutic target for bladder cancer.
\end{abstract}

\section{Introduction}

Bladder cancer is one of the most common urogenital cancers worldwide and the 7th leading cause of cancer-associated mortality (1). Approximately 79,000 new cases are diagnosed each year in the USA, of which there are an estimated 16,800 mortalities (2). During the last several decades, important advances have occurred in the diagnosis and treatment of bladder cancer, which have led to promising and significant

Correspondence to: Dr Jingjing Kong, Department of Anesthesia, The First People's Hospital of Jingmen, 67 Xiangshen Road, Jingmen, Hubei 448000, P.R. China

E-mail: anesthesiakong@sina.com

Key words: LIM and SH3 Protein 2, bladder cancer, progression, $\mathrm{Wnt} / \beta$-catenin improvements clinically; however the survival rate of patients with late-stage disease remained unfavorable (3). Additionally, the underlying mechanisms of bladder cancer progression are largely unknown (4). Therefore, studies have focused on the molecular mechanisms of bladder cancer development and the identification of novel molecular biomarkers $(5,6)$.

LIM and SH3 Protein 2 (LASP2) is a member of the nebulin family of actin-binding proteins characterized by a LIM motif and a Src homology region 3 domain (7). LASP2 was originally identified in chicken brains; the primary structure of LASP2 possesses a high degree of similarity with another nebulin family member, LASP1 (8). Like LASP1, LASP2 contains an N-terminal LIM domain, C-terminal SH3 domains and internal nebulin repeats (8). LASP1 and LASP2 are components of focal adhesions, and bind F-actin and zyxin (9). However, the sequence between the second nebulin repeat and the SH3 domain of LASP2 is markedly different from the sequence in the same area in LASP1 (8). The function of LASP2 has been linked to its LIM and SH3 domains. The LIM domain has been identified in diverse cellular functions in cell adhesion and signal transduction (10). The SH3 domain is characterized as a conserved sequence in the viral adaptor protein v-Crk, which is associated with the dynamics of the actin cytoskeleton (11). Therefore, the role of LASP-2 has been focused on focal adhesion function and organization. For example, Deng et al (12) revealed that LASP2 could increase the rate of attachment and migration of fibroblasts on fibronectin-coated surfaces, and may serve a role in cell proliferation. Recently, attention has focused on the function of LASP2 in tumorigenesis and tumor development $(13,14)$. However, the role of LASP2 in bladder cancer has not yet been elucidated.

In the present study, it was revealed that LASP2 was downregulated in bladder cancer, and that LASP2 expression was associated with the clinicopathological features of patients with bladder cancer. Overexpression of LASP2 effectively suppressed, while LASP2 depletion promoted the proliferation, migration and invasion of bladder cancer cells, and angiogenesis in bladder cancer. Furthermore, it was demonstrated that the Wnt/ $\beta$-catenin signaling pathway is associated with the tumor-suppressing effects of LASP2 in bladder cancer cells. Therefore, the data from the present study highlighted the biological role of LASP2 in bladder cancer progression, and suggested that it has potential value as a therapeutic target for this disease. 


\section{Materials and methods}

Cell lines. The bladder cancer cell line EJ (cat. no. CL-0274) was obtained from Procell Life Science and Technology Co., Ltd. (Wuhan, China), and 5637 (cat. no. TCHu 1), UM-UC-3 (cat. no. TCHu 217), T24 (cat. no. SCSP-536) and TCCSUP (cat. no. SCSP-571) bladder cancer cell lines were obtained from the Cell Bank of Chinese Academy of Sciences (Shanghai, China). The cells were maintained as described previously (15). Normal urothelial cells (provided by Huazhong University of Science and Technology, Wuhan, China) were obtained from fresh human bladder samples. All the cancer cell lines were cultured in RPMI 1640 medium (Hyclone; GE Healthcare Life Sciences, Logan, UT, USA) supplemented with $10 \%$ fetal bovine serum (FBS; Gibco; Thermo Fisher Scientific, Inc., Waltham, MA, USA) at $37^{\circ} \mathrm{C}$ in a $5 \% \mathrm{CO}_{2}$ atmosphere.

Tissue samples. A total of 196 bladder cancer RNA samples, which were retrieved from the archives of The First People's Hospital of Jingmen (Jingmen, China) were used for reverse transcription-quantitative polymerase chain reaction (RT-qPCR) analysis. A total of 60 pairs of snap-frozen bladder cancer and normal adjacent-noncancerous tissues (48 male and 12 female, aged from 43-70 years) for RT-qPCR analysis were obtained from The First People's Hospital of Jingmen between January 2016 and February 2017. All patients were pathologically staged according to the American Joint Committee on Cancer's classification system on TNM staging (16). For the use of these clinical materials for research purposes, informed consent from all patients and approval from the Institutional Research Ethics Committee of The First People's Hospital of Jingmen were obtained.

Western blotting analysis. Western blotting was performed according to standard methods as previously described (14). Cells and tissues were lysed with radioimmunoprecipitation assay lysis buffer (Biyuntian Biotechnology Research Institute, Nantong, China). The protein concentration of each lysate was determined with the BCA Protein Assay kit (Thermo Fisher Scientific, Inc.). Total proteins (30 $\mu \mathrm{g} /$ lane) were separated by $10 \%$ SDS-PAGE and transferred to a polyvinylidene difluoride (PVDF) membrane. The blots were blocked in 5\% milk for $1 \mathrm{~h}$ at room temperature. PVDF membranes were incubated using rabbit anti-LASP2 (1:100; cat. no. 260630; Sigma-Aldrich; Merck KGaA, Darmstadt, Germany), anti-cyclin D1 (1:10,000; cat. no. ab134175; Abcam, Cambridge, UK) and anti- $\beta$-catenin (1:1,000; cat. no. ab22656; Abcam) antibodies overnight at $4^{\circ} \mathrm{C}$. Subsequently, membranes were incubated with corresponding horseradish peroxidase-conjugated goat anti-rabbit secondary antibodies (1:5,000; cat. no. ab6112; Abcam) for $2 \mathrm{~h}$ at room temperature and detected using an enhanced chemiluminescence reagent (ECL Prime; GE Healthcare, Chicago, IL, USA). The anti- $\alpha$-tubulin (1:5,000; cat. no. ab4074; Abcam,) and anti-P84 (1:10,000; cat. no. ab131268; Abcam) antibodies were used as loading controls.

RNA extraction and RT-qPCR. Total RNA from cells and tissue samples were extracted using TRIzol reagent (Invitrogen; Thermo Fisher Scientific, Inc.), followed by the reverse transcription of RNA into cDNA using PrimeScript ${ }^{\mathrm{TM}}$ RT Master
Mix (Takara Biotechnology Co., Ltd., Dalian, China). The temperature protocol used for reverse transcription was: $25^{\circ} \mathrm{C}$ for $10 \mathrm{~min} ; 42^{\circ} \mathrm{C}$ for $50 \mathrm{~min}$; and $70^{\circ} \mathrm{C}$ for $15 \mathrm{~min}$. A SYBR PCR kit (Applied Biosystems; Thermo Fisher Scientific, Inc.) was used to amplify the first-strand cDNA following the manufacturer's protocol. Thermocycling was performed under the following conditions: $95^{\circ} \mathrm{C}$ for $5 \mathrm{~min}$ followed by 40 cycles of amplification at $95^{\circ} \mathrm{C}$ for $15 \mathrm{sec}$ and $60^{\circ} \mathrm{C}$ for $60 \mathrm{sec}$. GAPDH was used as an endogenous control. All samples were normalized to controls and fold changes were calculated by the $2^{-\Delta \Delta \mathrm{Cq}}$ method (17). The sequences of the primers are presented in Table I.

Vectors construction and siRNA transfection. T24 and EJ cells were seeded in 48 -well plates at a density of $2 \times 10^{5} /$ well. The full-length human LASP2 cDNA was amplified by PCR and cloned into pENTER vector (Shanghai GenePharma Co., Ltd., Shanghai, China). LASP2 siRNAs and scramble control siRNAs were synthesized from Shanghai GenePharma Co., Ltd. The siRNA sequences used to knockdown LASP2 were as follows: 5'-GUCCUAUGCUAA ACCAUGUTT-3' and 5'-ACAUGGUUUAGCAUAGGACTT-3', and the scramble control siRNA sequences were: 5'-UUUAUAGGCAGCAUC GCUGAC-3' and 5'-CAAUGCAGCAUUCACCAAATT-3'. The plasmid and LASP2-siRNA were transfected into cells at a final concentration of $1 \mathrm{mg} / \mathrm{ml}$ and $100 \mathrm{nM}$, respectively, by using Lipofectamine 2000 reagents (Invitrogen; Thermo Fisher Scientific, Inc.) according to the manufacturer's protocol. Knockdown was assessed by RT-qPCR after $48 \mathrm{~h}$ of transfection.

Labeling with 5-ethynyl-2'-deoxyuridine (EdU). Cell proliferation assays were carried out using EdU labeling. Cells (1x105/well) were plated in 96-well plates and cultured in RPMI 1640 medium. At 70-80\% confluence, cells were incubated with $50 \mu \mathrm{M}$ EdU (cat. no. R11053; Guangzhou RiboBio Co., Ltd., Guangzhou, China) for $3 \mathrm{~h}$ at $37^{\circ} \mathrm{C}$ and treated with $100 \mu 1$ 1X ApolloR reaction cocktail (Guangzhou RiboBio Co., Ltd.) according to the manufacturer's protocol. Finally, DAPI ( $1 \mu \mathrm{g} / \mathrm{ml}$; Sigma-aldrich; Merck KGaA) was added to the slide, and stained for $20 \mathrm{~min}$ at room temperature. All images were captured via fluorescence microscopy (magnification, x20). ImageJ 1.47 (National Institutes of Health, Bethesda, MD, USA) was used to analyze the resulting images.

Wound healing assay. T24 and EJ cells ( $5 \times 10^{5}$ cells/well) were seeded in 12-well plates and grown in RPMI 1640 medium at $37^{\circ} \mathrm{C}$ in a $5 \% \mathrm{CO}_{2}$ atmosphere. A scratch was created on each confluent monolayer using a $200-\mu 1$ plastic pipette tip and the cells were then incubated in serum-free RPMI 1640 medium at room temperature for $24 \mathrm{~h}$. The wound closure was calculated by examining the distance between the opposite edges of the wound using a light microscope (magnification, x20). Each sample was assayed in triplicate. ImageJ 1.47 was used to analyze the resulting images.

Transwell cell migration assay. The migration of cells was assessed using 24-well Transwell chambers with $8-\mu \mathrm{m}$ pore membranes (Corning Life Sciences, Corning, NY, USA). A total of $200 \mu \mathrm{l}$ cell medium $\left(1 \times 10^{5}\right.$ cells $/ 100 \mu \mathrm{l}$ in RPMI 1640 medium) were added to the upper chamber of each 
Table I. Reverse transcription-quantitative polymerase chain reaction primer sequences.

\begin{tabular}{lll}
\hline Gene & \multicolumn{1}{c}{ Forward primer $\left(5^{\prime}-3^{\prime}\right)$} & \multicolumn{1}{c}{ Reverse primer $\left(5^{\prime}-3^{\prime}\right)$} \\
\hline LASP2 & CATTCCCAAGGCTATGGCTA & ATCGTACATGGCTCGGTAGG \\
c-Myc & GGCTCCTGGCAAAAGGTCA & CTGCGTAGTTGGCTGATGT \\
c-Jun & TCCAAGTGCCGAAAAAGGAAG & CGAGTTCTGAGCTTTCAAGGT \\
CCND1 & CAATGACCCCGCACGATTTC & CATGGAGGGCGGATTGGAA \\
CTLA4 & CATGATGGGGAATGAGTTGACC & TCAGTCCTTGGATAGTGAGGTTC \\
LEF1 & ATGTCAACTCCAAACAAGGCA & CCCGGAGACAAGGGATAAAAAGT \\
TCF1 & TTGATGCTAGGTTCTGGTGTACC & CCTTGGACTCTGCTTGTGTC \\
AXIN2 & ACTGCCCACACGATAAGGAG & CTGGCTATGTCTTTGGACCA \\
GAPDH & TCAAGAAGGTGGTGAAGCAG & CGTCAAAGGTGGAGGAGTG
\end{tabular}

LASP2, LIM and SH3 Protein 2; CCND1, cyclin D1; CTLA4, cytotoxic T lymphocyte associated protein 4; LEF1, lymphoid enhancer binding factor 1 ; TCF1, T cell factor 1 .

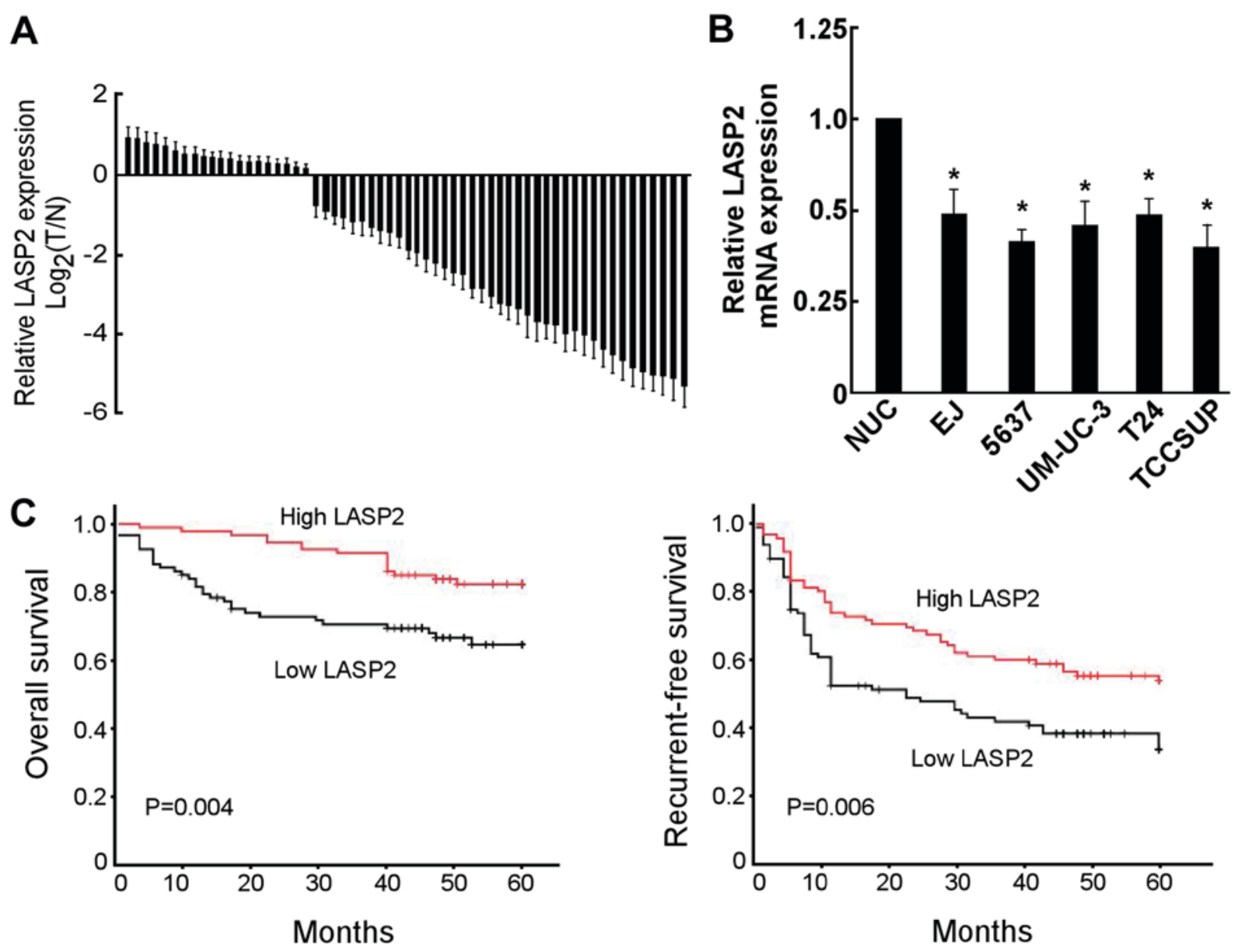

Figure 1. LASP2 expression is decreased in patients with bladder cancer. (A) LASP2 mRNA expression in 60 pairs of bladder cancer and adjacent non-tumor tissues. (B) LASP2 mRNA expression in NUCs and bladder cancer cell lines (EJ, 5637, UM-UC-3, T24 and TCCSUP). "P<0.05 vs NUC. (C) Kaplan-Meier analysis of overall and recurrent-free survival rates stratified by low and high LASP2 expression (n=98/group). LASP2, LIM and SH3 Protein 2; NUC, normal urothelial cell; $\mathrm{T} / \mathrm{N}$, tumor/normal.

Transwell chamber. Medium containing 10\% FBS (HyClone; GE Healthcare Life Sciences) was added to the lower chamber. After incubating the cells for $24 \mathrm{~h}$, the cells were fixed in $4 \%$ paraformaldehyde (Sigma-Aldrich; Merck KGaA) at $0^{\circ} \mathrm{C}$ for $20 \mathrm{~min}$ and stained with $0.1 \%$ crystal violet for $15 \mathrm{~min}$ at $25^{\circ} \mathrm{C}$ for visualization using a light microscope (magnification, $\mathrm{x} 20)$. Migrated cells were measured by image analysis software (ImagePro Plus 6.0; Media Cybernetics, Inc., Rockville, MD, USA). Experiments were performed in triplicate. For cell invasion experiments, Matrigel (BD Biosciences) was plated inside Transwell culture inserts, with the same protocol being followed. 
Table II. Association between LASP2 mRNA expression and clinicopathological characteristics.

\begin{tabular}{|c|c|c|c|c|c|}
\hline \multirow[b]{2}{*}{ Characteristics } & \multirow[b]{2}{*}{ Patients (n) } & \multicolumn{2}{|c|}{ LASP2 expression } & \multirow[b]{2}{*}{$\chi^{2}$} & \multirow[b]{2}{*}{ P-value } \\
\hline & & Low & High & & \\
\hline Sex & & & & 0.022 & 0.883 \\
\hline Male & 121 & 60 & 61 & & \\
\hline Female & 75 & 38 & 37 & & \\
\hline Age (years) & & & & 1.649 & 0.775 \\
\hline$\leq 60$ & 92 & 47 & 45 & & \\
\hline$>60$ & 104 & 51 & 53 & & \\
\hline Tumor grade & & & & 0.191 & 0.662 \\
\hline Low & 117 & 57 & 60 & & \\
\hline High & 79 & 41 & 38 & & \\
\hline Tumor size & & & & 5.819 & $0.016^{\mathrm{a}}$ \\
\hline$<3 \mathrm{~cm}$ & 143 & 64 & 79 & & \\
\hline$\geq 3 \mathrm{~cm}$ & 53 & 34 & 19 & & \\
\hline $\mathrm{T}$ classification & & & & 11.056 & $0.001^{\mathrm{a}}$ \\
\hline $\mathrm{Ta}$ and $\mathrm{T} 1$ & 130 & 54 & 76 & & \\
\hline $\mathrm{T} 2-\mathrm{T} 4$ & 66 & 44 & 22 & & \\
\hline Total & 196 & 98 & 98 & & \\
\hline
\end{tabular}

LASP2, LIM and SH3 Protein 2. ${ }^{\mathrm{a} P}<0.05$.

Human umbilical vein endothelial cells (HUVECs) tube formation assay. Precooled Matrigel (Corning Life Sciences) was plated into each well of a 24-well plate and allowed to set into a gel for $30 \mathrm{~min}$ at $37^{\circ} \mathrm{C}$. HUVECs $\left(5 \times 10^{4} /\right.$ well; Cell Bank of the Chinese Academy of Sciences, Shanghai, China) in $200 \mu \mathrm{l}$ F-12K medium (Hyclone; GE Healthcare Life Sciences) were added to each well and incubated at $37^{\circ} \mathrm{C}$ in $5 \% \mathrm{CO}_{2}$ for $20 \mathrm{~h}$. The capillary tube structure was photographed using a light microscope (magnification, x20) and quantified by measuring the total length of the completed tubes. Image J 1.47 was used to analyze the resulting images.

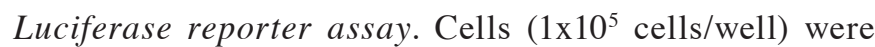
seeded in 96-well plates and allowed to settle for $12 \mathrm{~h}$ at $37^{\circ} \mathrm{C}$. Reporter plasmids (100 ng; EMD Millipore, Billerica, MA, USA) containing wild-type (CCTTTGATC; TOP flash) or mutated (CCTTTGGCC; FOP flash) T-cell factor/lymphoid enhancer-binding factor (TCF/LEF) binding sites used to determine $\beta$-catenin transcriptional activity (18) plus $1 \mathrm{ng}$ pRL-TK Renilla plasmid were co-transfected using Lipofectamine 2000 according to the manufacturer's protocol. Firefly and Renilla luciferase activity were measured $48 \mathrm{~h}$ following transfection using the Dual Luciferase Reporter Assay kit (Promega Corporation, Madison, WI, USA) according to manufacturer's protocol. Luciferase activity was normalized to Renilla luciferase activity. All experiments were performed in triplicate.

Statistical analysis. SPSS 16.0 (SPSS, Inc., Chicago, IL, USA) was used for statistical analysis. The one-way analysis of variance was performed, followed by Student-Newman-Keuls post-hoc test. The association between LASP2 expression and the clinicopathological characteristics was analyzed via Pearson's $\chi^{2}$ test. The overall survival was calculated as the time from the date of primary surgery to the date of death or the date of the last follow-up. Recurrent-free survival was defined as the time from the date of primary surgery to the date of first recurrence or the date of the last follow-up. Kaplan-Meier analysis and log-rank test were used to perform survival analyses. The clinicopathological characteristics was evaluated by two pathologists, and the association between variables (sex, age, tumor grade, tumor size, T classification using the TNM staging system and LASP2 expression level) survival rates were analyzed by the Cox proportional hazards model for univariate and multivariate analyses. $\mathrm{P}<0.05$ indicated that the difference between groups was statistically significant.

\section{Results}

LASP2 is downregulated in patients with bladder cancer. To reveal the function of LASP2 in bladder cancer, RT-qPCR was performed to examine the LASP2 expression in bladder cancer tissues and cell lines. As presented in Fig. 1A, LASP2 mRNA expression was decreased in $75.0 \%$ (45/60) of patients. Furthermore, LASP2 was significantly decreased in bladder cancer cell lines compared with normal urothelial cells (Fig. 1B).

LASP2 is associated with the clinicopathological characteristics of patients with bladder cancer. The association between LASP2 expression and clinicopathological features was further investigated in bladder cancer patients. Statistical analyses 
Table III. Univariate analysis in patients with bladder cancer.

\begin{tabular}{|c|c|c|c|c|}
\hline \multirow[b]{2}{*}{ Prognostic variables } & \multicolumn{2}{|c|}{ Overall survival } & \multicolumn{2}{|c|}{ Recurrent-free survival } \\
\hline & Hazard ratio $(95 \% \mathrm{CI})$ & P-value & Hazard ratio $(95 \% \mathrm{CI})$ & P-value \\
\hline Sex (male vs. female) & $1.576(0.832-2.986)$ & 0.163 & $1.353(0.854-2.875)$ & 0.255 \\
\hline $\operatorname{Age}(>60$ vs. $\leq 60$ years $)$ & $1.343(0.750-2.405)$ & 0.321 & $1.028(0.695-1.520)$ & 0.892 \\
\hline Tumor grade (high vs. low) & $2.784(1.383-5.640)$ & $0.004^{\mathrm{a}}$ & $2.569(1.024-2.406)$ & $0.039^{\mathrm{a}}$ \\
\hline Tumor size ( $\geq 3$ vs. $<3 \mathrm{~cm})$ & $1.275(0.535-2.634)$ & $0.024^{\mathrm{a}}$ & $1.652(0.936-2.909)$ & 0.082 \\
\hline $\mathrm{T}$ classification (T2-4 vs. $\mathrm{T} 1$ and $\mathrm{Ta}$ ) & $1.333(0.744-2.387)$ & $0.033^{\mathrm{a}}$ & $1.779(0.509-2.195)$ & $0.025^{\mathrm{a}}$ \\
\hline LASP2 (high vs. low) & $0.421(0.220-0.771)$ & $0.005^{\mathrm{a}}$ & $0.445(0.734-0.782)$ & $0.012^{\mathrm{a}}$ \\
\hline
\end{tabular}

CI, confidence interval; LASP2, LIM and SH3 Protein 2. ${ }^{\mathrm{a}} \mathrm{P}<0.05$.

A
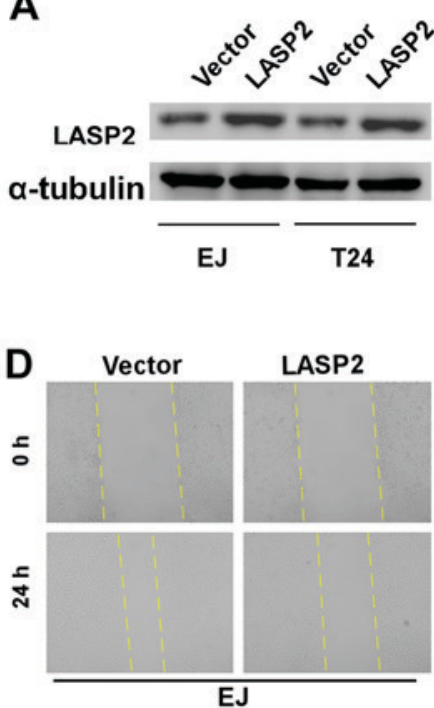
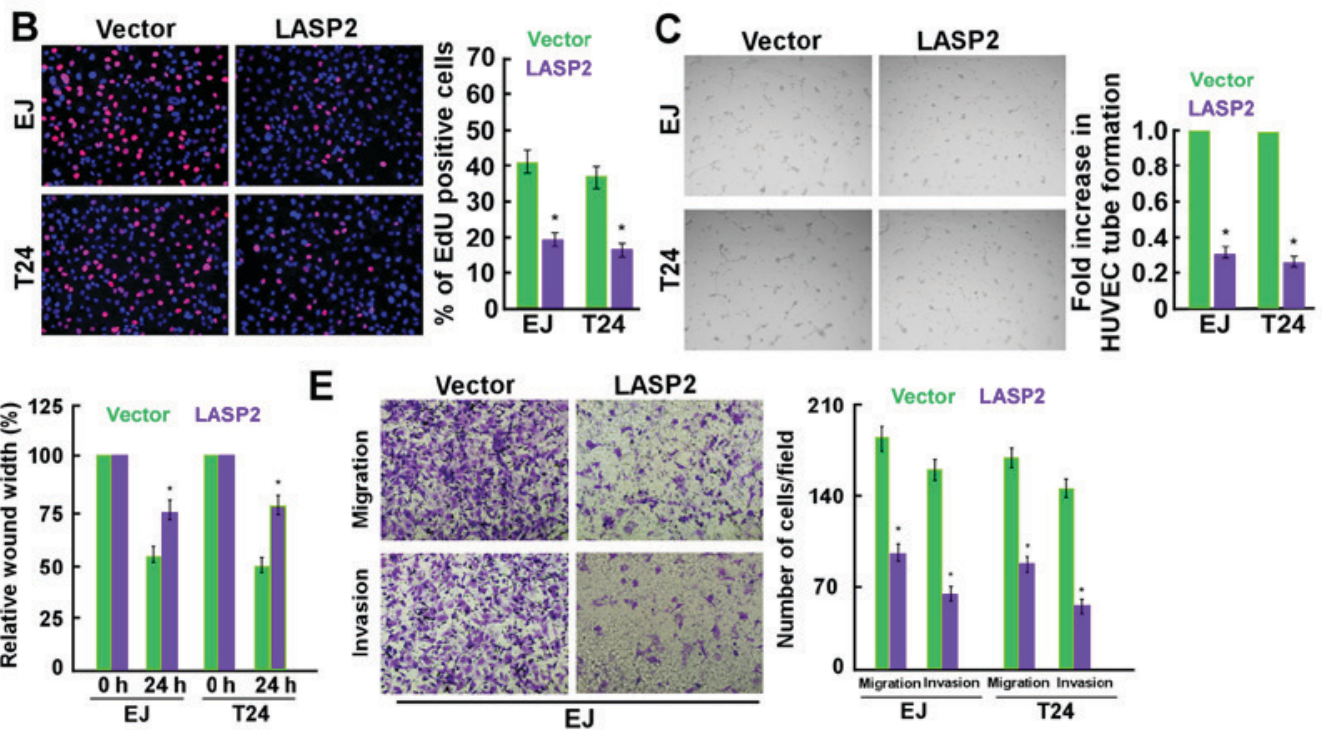

Figure 2. LASP2 upregulation inhibits bladder cancer cell aggressiveness. (A) Western blotting analysis of LASP2 expression in EJ and T24 cells. (B) Representative images (left panel, x200) and quantification (right panel) of EdU incorporation in EJ and T24 bladder cancer cells. DAPI was used as a DNA stain. Representative images (left panel) and quantification (right panel) of (C) HUVECs cultured on Matrigel-coated plates with conditioned medium from LASP2-overexpressing cells, (magnification, x200) (D) migratory cells assessed using a wound healing assay and (E) migratory cells assessed using Transwell migration and Matrigel invasion assays, respectively (magnification, x200). *P<0.05. EdU, 5-ethynyl-2'-deoxyuridine; HUVEC, human umbilical vein endothelial cell; LASP2, LIM and SH3 Protein 2.

revealed that the expression of LASP2 was significantly associated with tumor size and tumor stage (Table II). In the Kaplan-Meier analysis, the cut-off point (relative value, -2.34) of LASP2 mRNA expression was defined as the median (low LASP2 group, 49 months; high LASP2 group, 48 months). The results revealed that the overall and recurrent-free survival times of patients with low LASP2 expression was significantly shorter compared with those with high LASP2 expression (Fig. 1C). Univariate and multivariate analyses revealed that LASP2 expression was an independent prognostic factor for overall and recurrent-free survival in patients with bladder cancer (Tables III and IV).

LASP2 inhibits bladder cancer cell proliferation, migration and invasion, and angiogenesis in vitro. The effects of LASP2 on cell proliferation, migration and invasion, and angiogenesis were then evaluated in EJ and T24 cells through overexpressing and inhibiting LASP2 expression (Figs. 2 and 3). LASP2 overexpression was confirmed via western blotting (Fig. 2A). The EdU labeling assay revealed that upregulated LASP2 expression inhibited the proliferation of the two cell lines (Fig. 2B). In addition, the overexpression of LASP2 significantly decreased the ability of bladder cancer cells to induce tube formation by HUVECs (Fig. 2C). The results of wound healing and Transwell migration assay suggested that tumor migration was significantly decreased following the transfection of LASP2 plasmids into EJ cells (Fig. 2D and E). Also, the Matrigel invasion assay suggested that tumor invasion decreased following the transfection of LASP2 plasmids into EJ cells (Fig. 2E). In contrast, LASP2 inhibition significantly promoted cell proliferation, invasion and migration and angiogenesis (Fig. 3).

LASP2 mediates the Wnt/ $\beta$-catenin signaling pathway in bladder cancer cells. The molecular mechanism by which LASP2 exerts its biological function was further explored. As 
Table IV. Multivariate analysis in patients with bladder cancer.

\begin{tabular}{|c|c|c|c|c|}
\hline \multirow[b]{2}{*}{ Prognostic variables } & \multicolumn{2}{|c|}{ Overall survival } & \multicolumn{2}{|c|}{ Recurrent-free survival } \\
\hline & Hazard ratio $(95 \% \mathrm{CI})$ & P-value & Hazard ratio $(95 \% \mathrm{CI})$ & P-value \\
\hline Sex (male vs. female) & - & - & - & - \\
\hline Age ( $>60$ vs. $\leq 60$ years) & - & - & - & - \\
\hline Tumor grade (high vs. low) & $2.861(1.576-5.196)$ & 0.001 & - & - \\
\hline Tumor size ( $\geq 3$ vs. $<3 \mathrm{~cm}$ ) & - & - & - & - \\
\hline T classification (T2-4 vs. T1 and Ta) & $1.924(1.024-3.614)$ & 0.042 & - & - \\
\hline LASP2 (high vs. low) & $0.298(0.154-0.579)$ & $<0.001$ & $0.585(0.394-0.870)$ & 0.008 \\
\hline
\end{tabular}

CI, confidence interval; LASP2, LIM and SH3 Protein 2.
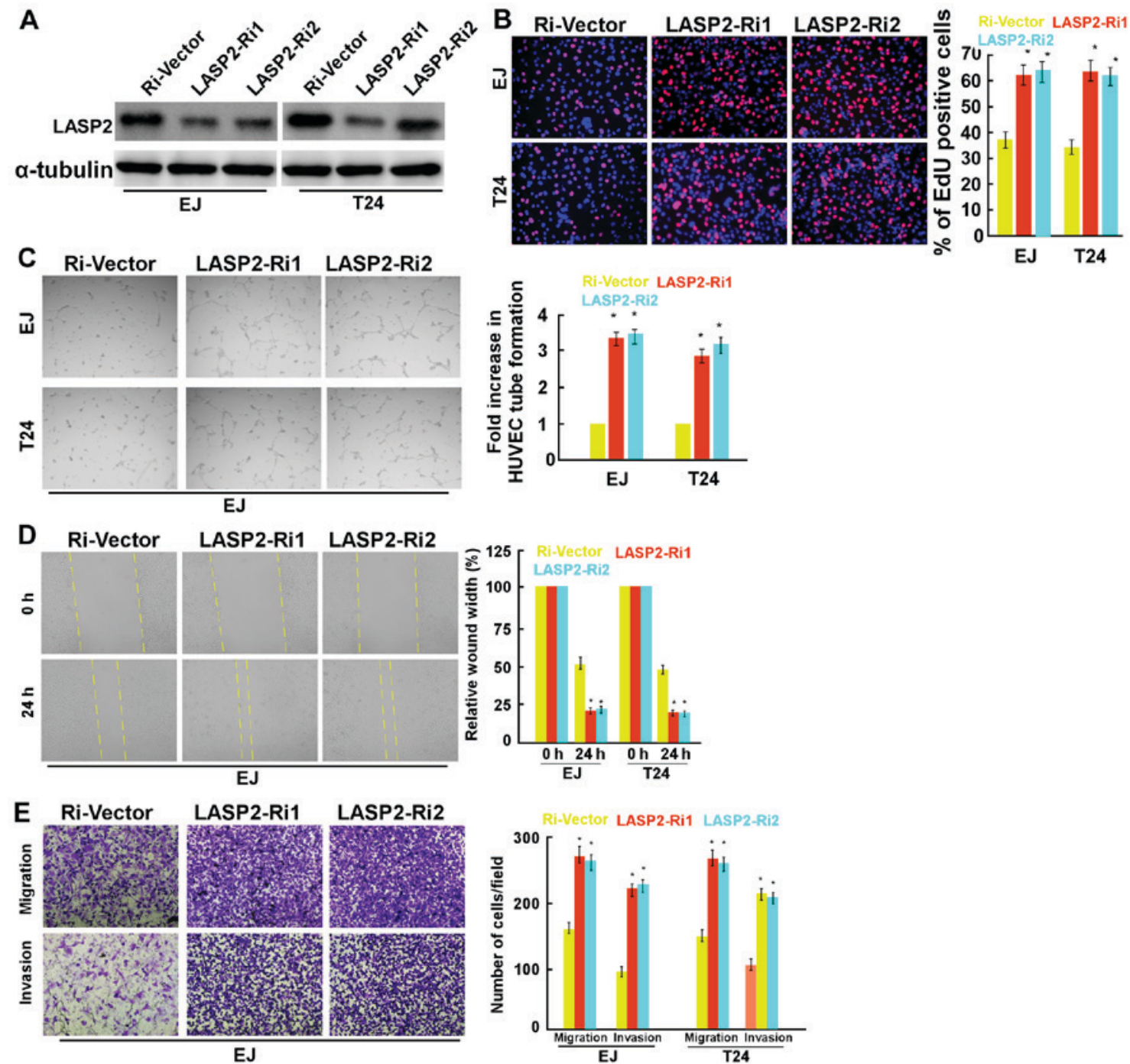

Figure 3. LASP2 downregulation promotes bladder cancer cell aggressiveness. (A) Western blotting analysis of LASP2 expression in LASP2 knockdown EJ and T24 cells. (B) Representative images (left panel) and quantification (right panel) of EdU incorporation in EJ and T24 bladder cancer cells. DAPI was used as a DNA stain. Representative images (left panel) and quantification (right panel) of (C) HUVECs cultured on Matrigel-coated plates with conditioned medium from LASP2-silenced cells, (D) migratory cells assessed using a wound healing assay and (E) migratory cells assessed using transwell migration and Matrigel invasion assays, respectively. "P<0.05. EdU, 5-ethynyl-2'-deoxyuridine; HUVEC, human umbilical vein endothelial cell; LASP2, LIM and SH3 Protein 2; Ri, RNA interference.

presented in Fig. 4A, LASP2 upregulation significantly inhibited, whereas LASP2 knockdown significantly increased the transactivation activity of $\beta$-catenin/TCF in the two cell lines using the luciferase reporter assay. Furthermore, the expression 
A

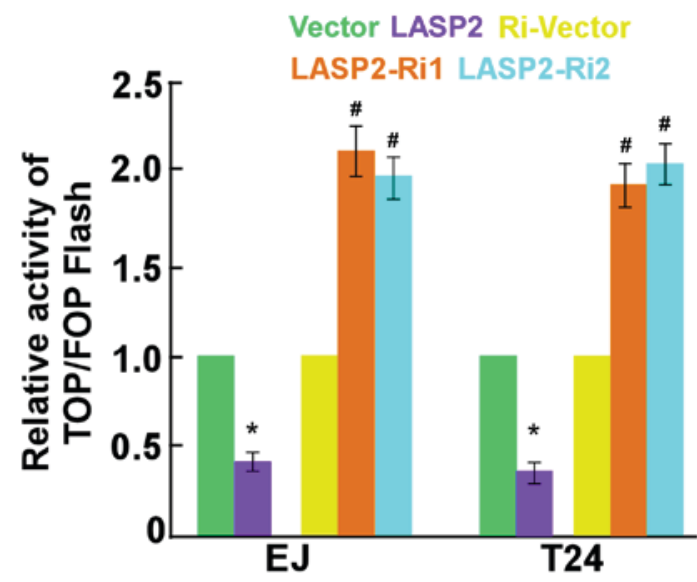

B

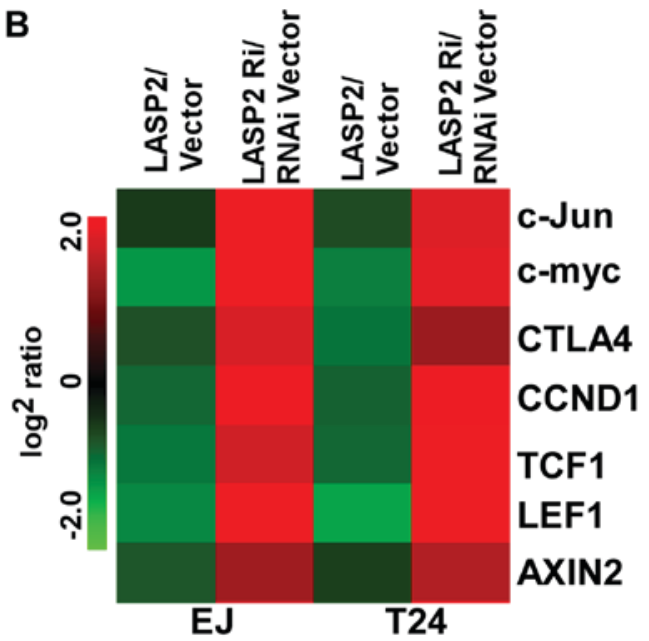

Figure 4. LASP2 inactivates the Wnt/ $\beta$-catenin signaling pathway. (A) TOP/FOP luciferase assay of T-cell factor/lymphoid enhancer-binding factor transcriptional activity in transfected EJ and T24 cells. ${ }^{*} \mathrm{P}<0.05$ vs Ri-Vector. (B) Reverse transcription-quantitative polymerase chain reaction analysis of downstream genes of the Wnt/ $\beta$-catenin signaling pathway in transfected EJ and T24 cells. ${ }^{*} \mathrm{P}<0.05$ vs. Vector. ${ }^{\text {P }}<0.05$. LASP2, LIM and SH3 Protein 2 ; Ri, RNA interference.

levels of downstream targets of the Wnt/ $\beta$-catenin signaling pathway, including c-Myc, c-Jun, cyclin D1 (CCND1), cytotoxic $\mathrm{T}$ lymphocyte associated protein 4 , lymphoid enhancer binding factor $1, \mathrm{~T}$ cell factor 1 and AXIN2 were markedly lower in LASP2-overexpressing tumor cells compared with that in LASP2-silenced cells (Fig. 4B). Western blotting assays were also performed to demonstrate that LASP2 expression was negatively associated with CCNDlexpression and nuclear $\beta$-catenin expression (Fig. 5).

\section{Discussion}

The results of the current study demonstrated that LASP2 functions as a tumor suppressor in bladder cancer. Low LASP2 expression was frequently detected in bladder cancer, and was associated with larger tumor size, advanced TNM staging (i.e. $\mathrm{T}$ classification) and poor prognosis. Additionally, the overexpression of LASP2 attenuates the proliferation, migration and invasion of bladder cancer cells, and angiogenesis via the regulation of Wnt/ $\beta$-catenin signaling pathway. These findings suggest that LASP2 may serve as a prognostic marker for patients with bladder cancer and an important role in bladder cancer progression.

Nebulin family members, with molecular weights ranging from 34-900 kDa, have diverse expression patterns and cellular functions (19). The majority of nebulin family members contain the defining characteristic of actin-binding domains referred to as 'nebulin repeats' through which the members form multi-domain proteins to interact with filamentous actin (20). The nebulin protein family has been proposed to serve essential physiological roles in human diseases. For example, mutations in nebulin were demonstrated to be the main cause of the human muscle disorder nemaline myopathy, and subsequent distal and core-rod myopathies (21). The abnormal expression of nebulette or N-RAP genes have been associated with dilated cardiomyopathy (22). As a shorter splice variant of nebulette, LASP2 is a novel nebulin family member (23). In cardiomyocytes, LASP2 is localized in

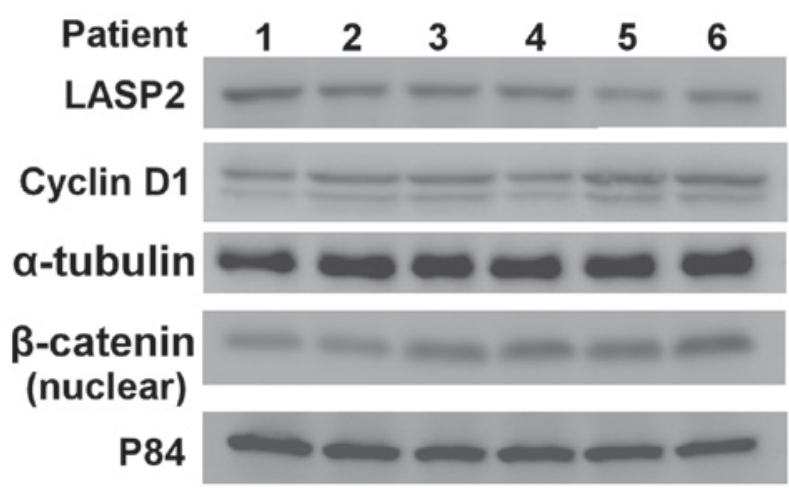

Figure 5. LASP2 is associated with proteins in the Wnt/ $\beta$-catenin signaling pathway in bladder cancer cells. Western blotting results of LASP2, cyclin D1 and nuclear $\beta$-catenin expression in six samples from patients with bladder cancer. Nuclear matrix protein P84 was used as a loading control. LASP2, LIM and SH3 Protein 2.

different cytotskeletal structures, including the intercalated discs, Z-discs and focal adhesions, implying that LASP2 may act as a molecular scaffold that is important for cell migration and adhesion, and focal adhesion turnover $(24,25)$.

Recent data revealed that LASP2 is associated with the development of human cancers. Wang et al (14) recently demonstrated that LASP2 functions as a tumor suppressor gene in colon cancer and inhibits cancer progression via the c-Jun N-terminal kinase/p38 mitogen-activated protein kinase signaling pathway. In contrast, Zhang et al (13) reported that LASP2 acts as an oncogene in non-small-cell lung carcinoma (NSCLC) and accelerates tumor invasion through facilitating the phosphorylation of focal adhesion kinase. These studies indicate the diverse roles of LASP2 in different cancers. In the present study, the downregulation of LASP2 expression in bladder cancer was detected. Additionally, LASP2 expression was associated with larger tumor size and advanced TNM staging. In addition, functional experiments indicated that LASP2 could attenuate bladder cancer aggression. Together, these findings indicate that LASP2 may perform different functions in different cancers. 
Importantly, it was demonstrated that increased expression of LASP2 was associated with the reduction in the nuclear translocation of $\beta$-catenin in bladder cancer cells. Additionally, it was revealed that LASP2 downregulates the expression of downstream genes of the Wnt/ $\beta$-catenin signaling pathway. Together, the findings revealed that the tumor-suppressing role of LASP 2 in bladder cancer may be associated with Wnt/ $\beta$-catenin signaling pathway inactivation. The findings highlighted the importance of the Wnt/ $\beta$-catenin signaling pathway in bladder cancer progression, and may partially explain the different roles for LASP2 in different cancer types. Notably, it was demonstrated that the upregulation of LASP2 inhibited, whereas the knocking down of LASP2 induced HUVEC tube formation, revealing the role of LASP2 in angiogenesis.

The clinical significance of nebulin family proteins has been illustrated in previous studies. Qiu et al (26) demonstrated that nebulette overexpression in patients with colorectal cancer was associated with increased overall survival. Yang et al (27) suggested that LASP1 may serve as a prognostic biomarker for patients with clear cell renal cell carcinoma. Zhang et al (13) reported that the expression of LASP-2 was significantly correlated with poor prognosis in patients with NSCLC. The current study revealed that high LASP2 expression was associated with favorable overall and recurrent-free survival rates in patients with bladder cancer, further suggesting that LASP2 may be a marker used to predict the prognosis of patients with cancer.

The present study has several limitations. First, the retrospective, observational nature of the current study with unknown factors may affect the studied outcomes and were not captured in the present data collection. Second, only 196 patients were included; further studies on larger populations are required to confirm the preliminary results of the current study.

In summary, the present study has demonstrated that LASP2 has an important role in bladder carcinogenesis. LASP2 was revealed to mediate bladder cancer cell proliferation and metastasis, and angiogenesis in bladder cancer via the Wnt/ $\beta$-catenin signaling pathway. In addition, LASP 2 may function as an independent prognostic marker for bladder cancer. Thus, LASP2 could be a promising therapeutic target for the future treatment of bladder cancer.

\section{Acknowledgements}

Not applicable.

\section{Funding}

The present study was supported by the Innovation Fund of The First People's Hospital of Jingmen (grant no. 20154567).

\section{Availability of data and materials}

All data analyzed during the present study are included in this manuscript.

\section{Authors' contributions}

RY participated in data collection and drafted the manuscript. ZL performed the statistical analysis. YC and JK participated in the design of the study. All authors analyzed and interpreted the patient data.

\section{Ethics approval and consent to participate}

The present study was approved by the Institutional Research Ethics Committee of the The First People's Hospital of Jingmen (Jingmen, China). All patients provided written informed consent.

\section{Patient consent for publication}

Written informed consent was obtained from each patient for the use of the tissue samples for paper publication.

\section{Competing interests}

The authors declare that they have no competing interests.

\section{References}

1. Chen W, Zheng R, Baade PD, Zhang S, Zeng H, Bray F, Jemal A, Yu XQ and He J: Cancer statistics in China, 2015. CA Cancer J Clin 66: 115-132, 2016.

2. Siegel RL, Miller KD and Jemal A: Cancer statistics, 2016. CA Cancer J Clin 66: 7-30, 2016.

3. Madersbacher S, Hochreiter W, Burkhard F, Thalmann GN Danuser H, Markwalder R and Studer UE: Radical cystectomy for bladder cancer today-a homogeneous series without neoadjuvant therapy. J Clin Oncol 21: 690-696, 2003.

4. Volanis D, Papadopoulos G, Doumas K, Gkialas I and Delakas D: Molecular mechanisms in urinary bladder carcinogenesis. J BUON 16: 589-601, 2011.

5. Chen Z, Zhou L, Liu X, Wang L, Kazobinka G, Zhang X and Hou T: Loss of Fezf 2 promotes malignant progression of bladder cancer by regulating the NF- $\kappa \mathrm{B}$ signaling pathway. Lab Invest 98 : 1225-1236, 2018

6. Soria F, D'Andrea D, Pohar K, Shariat SF and Lotan Y: Diagnostic, prognostic and surveillance urinary markers in nonmuscle invasive bladder cancer: Any role in clinical practice? Curr Opin Urol, 27 Aug 2018 (Epub ahead of print).

7. Chew CS, Chen X, Parente JA Jr, Tarrer S, Okamoto C and Qin HY: Lasp-1 binds to non-muscle F-actin in vitro and is localized within multiple sites of dynamic actin assembly in vivo. J Cell Sci 115: 4787-4799, 2002.

8. Terasaki AG, Suzuki H, Nishioka T, Matsuzawa E, Katsuki M, Nakagawa H, Miyamoto S and Ohashi K: A novel LIM and SH3 protein (lasp-2) highly expressing in chicken brain. Biochem Biophys Res Commun 313: 48-54, 2004.

9. Li B, Zhuang L and Trueb B: Zyxin interacts with the SH3 domains of the cytoskeletal proteins LIM-nebulette and Lasp-1. J Biol Chem 279: 20401-20410, 2004.

10. Kadrmas JL and Beckerle MC: The LIM domain: From the cytoskeleton to the nucleus. Nat Rev Mol Cell Biol 5: 920-931, 2004.

11. Stradal TE and Scita G: Protein complexes regulating Arp2/3-mediated actin assembly. Curr Opin Cell Biol 18: 4-10, 2006.

12. Deng XA, Norris A, Panaviene Z and Moncman CL: Ectopic expression of LIM-nebulette (LASP2) reveals roles in cell migration and spreading. Cell Motil Cytoskeleton 65: 827-840, 2008.

13. Zhang X, Cai L, Zhou H, Liu Y, Fan C, Wang L, Li A, Miao Y, Li Q, Qiu X and Wang E: Lasp2 enhances tumor invasion via facilitating phosphorylation of FAK and predicts poor overall survival of non-small cell lung cancer patients. Mol Carcinog 56: 2558-2565, 2017.

14. Wang B, Zhang L, Zhao L, Zhou R, Ding Y, Li G and Zhao L: LASP2 suppresses colorectal cancer progression through JNK/p38 MAPK pathway meditated epithelial-mesenchymal transition. Cell Commun Signal 15: 21, 2017.

15. Yang C, Zhang W, Wang L, Kazobinka G, Han X, Li B and Hou T: Musashi-2 promotes migration and invasion in bladder cancer via activation of the JAK2/STAT3 pathway. Lab Invest 96: 950-958, 2016. 
16. Wang G and McKenney JK: Urinary bladder pathology: World Health Organization (WHO) classification and american joint committee on cancer (AJCC) staging update. Arch Pathol Lab Med, $25 \mathrm{Jul} 2018$ (Epub ahead of print).

17. Livak KJ and Schmittgen TD: Analysis of relative gene expression data using real-time quantitative PCR and the 2(-Delta Delta C(T)) method. Methods 25: 402-408, 2001.

18. Zhang N, Wei P, Gong A, Chiu WT, Lee HT, Colman H, Huang H, Xue J, Liu M, Wang Y, et al: FoxM1 promotes $\beta$-catenin nuclear localization and controls Wnt target-gene expression and glioma tumorigenesis. Cancer Cell 20: 427-442, 2011.

19. Kazmierski ST, Antin PB, Witt CC, Huebner N, McElhinny AS, Labeit $\mathrm{S}$ and Gregorio CC: The complete mouse nebulin gene sequence and the identification of cardiac nebulin. $\mathrm{J}$ Mol Biol 328: 835-846, 2003.

20. Pappas CT, Bliss KT, Zieseniss A and Gregorio CC: The Nebulin family: An actin support group. Trends Cell Biol 21: 29-37, 2011.

21. Romero NB, Lehtokari VL, Quijano-Roy S, Monnier N, Claeys KG, Carlier RY, Pellegrini N, Orlikowski D, Barois A, Laing NG, et al: Core-rod myopathy caused by mutations in the nebulin gene. Neurology 73: 1159-1161, 2009.

22. Ehler E, Horowits R, Zuppinger C, Price RL, Perriard E, Leu M, Caroni P, Sussman M, Eppenberger HM and Perriard JC: Alterations at the intercalated disk associated with the absence of muscle LIM protein. J Cell Biol 153: 763-772, 2001.
23. Katoh $\mathrm{M}$ and Katoh M: Identification and characterization of LASP2 gene in silico. Int J Mol Med 12: 405-410, 2003.

24. Zieseniss A, Terasaki AG and Gregorio CC: Lasp-2 expression, localization, and ligand interactions: A new Z-disc scaffolding protein. Cell Motil Cytoskeleton 65: 59-72, 2008.

25. Panaviene $Z$ and Moncman CL: Linker region of nebulin family members plays an important role in targeting these molecules to cellular structures. Cell Tissue Res 327: 353-369, 2007.

26. Qiu X, Feng JR, Wang F, Chen PF, Chen XX, Zhou R, Chang Y, Liu J and Zhao Q: Profiles of differentially expressed genes and overexpression of NEBL indicates a positive prognosis in patients with colorectal cancer. Mol Med Rep 17: 3028-3034, 2018.

27. Yang F, Zhou X, Du S, Zhao Y, Ren W, Deng Q, Wang F and Yuan J: LIM and SH3 domain protein 1 (LASP-1) overexpression was associated with aggressive phenotype and poor prognosis in clear cell renal cell cancer. PLoS One 9: e100557, 2014.

This work is licensed under a Creative Commons Attribution-NonCommercial-NoDerivatives 4.0 International (CC BY-NC-ND 4.0) License. 